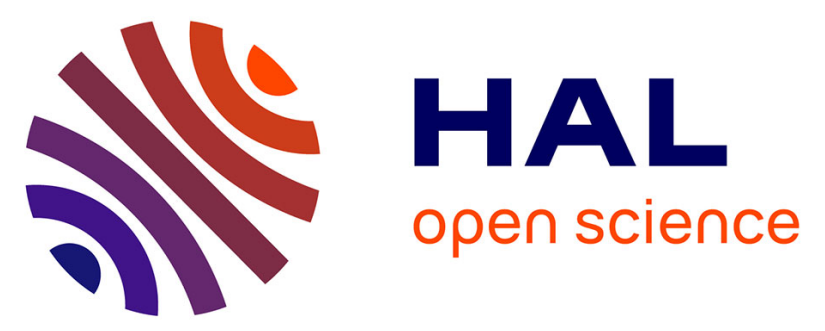

\title{
Transverse magnetic mode nonreciprocal propagation in an amplifying AlGaInAs/ InP optical waveguide isolator
}

Wouter Van Parys, Bart Moeyersoon, Dries van Thourhout, Roel Baets, Mathias Vanwolleghem, Beatrice Dagens, Jean Decobert, Odile Le Gouezigou, Dalila Make, Reinier Vanheertum, et al.

\section{- To cite this version:}

Wouter Van Parys, Bart Moeyersoon, Dries van Thourhout, Roel Baets, Mathias Vanwolleghem, et al.. Transverse magnetic mode nonreciprocal propagation in an amplifying AlGaInAs/ InP optical waveguide isolator. Applied Physics Letters, 2006, 10.1063/1.2174106 . hal-03327993

\section{HAL Id: hal-03327993 https://hal.science/hal-03327993}

Submitted on 27 Aug 2021

HAL is a multi-disciplinary open access archive for the deposit and dissemination of scientific research documents, whether they are published or not. The documents may come from teaching and research institutions in France or abroad, or from public or private research centers.
L'archive ouverte pluridisciplinaire HAL, est destinée au dépôt et à la diffusion de documents scientifiques de niveau recherche, publiés ou non, émanant des établissements d'enseignement et de recherche français ou étrangers, des laboratoires publics ou privés. 


\title{
Transverse magnetic mode nonreciprocal propagation in an amplifying AIGalnAs/InP optical waveguide isolator
}

\author{
Wouter Van Parys, ${ }^{\text {a) }}$ Bart Moeyersoon, Dries Van Thourhout, and Roel Baets \\ Department of Information Technology, Ghent University-IMEC, St-Pietersnieuwstraat 41, 9000 Gent, \\ Belgium \\ Mathias Vanwolleghem \\ Université Paris-Sud, Institut d'Electronique Fondamentale, 91405 Orsay Cedex, France
}

Beatrice Dagens, Jean Decobert, Odile Le Gouezigou, and Dalila Make Alcatel CIT, Route de Nozay, 91460 Marcoussis, France

Reinier Vanheertum and Liesbet Lagae

Interuniversitair Micro-Elektronica Centrum, IMEC vzw, Kapeldreef 75, 3001 Leuven, Belgium

(Received 1 August 2005; accepted 3 January 2006; published online 15 February 2006)

\begin{abstract}
The design, fabrication, and characterization of an amplifying transverse magnetic (TM)-mode optical waveguide isolator operating at a wavelength of $1300 \mathrm{~nm}$ are presented. The magneto-optical Kerr effect induces nonreciprocal modal absorption in a semiconductor optical amplifier with a laterally magnetized ferromagnetic metal contact. Current injection in the active structure compensates for the loss in the forward propagation direction. Monolithic integration of this optical isolator configuration with active InP-based photonic devices is straightforward. The combination of AlGaInAs/InP active material and the metal alloy $\mathrm{Co}_{50} \mathrm{Fe}_{50}$ results in greatly improved performance. $99 \mathrm{~dB} / \mathrm{cm}$ TM mode isolation and significantly reduced insertion loss are demonstrated. (C) 2006 American Institute of Physics. [DOI: 10.1063/1.2174106]
\end{abstract}

An optical isolator allows to avoid one of the main noise sources in an optical communication system by blocking optical feedback in the laser source. Current commercial isolators are bulk components requiring collimating lenses and expensive alignment techniques when applied in a laser diode package. Development of an integrated laser-isolator system is highly desirable as it would reduce cost and size and enhance mechanical and thermal stability. The cost reduction of a laser diode package would be the largest with directly modulated lasers, operating at $1300 \mathrm{~nm}$. Traditional research focuses on applying ferrimagnetic garnets to induce nonreciprocity. ${ }^{1}$ The interest in this class of materials comes from their unique combination of low optical loss at telecom wavelengths and a considerably strong magneto-optical (MO) effect, the source of the nonreciprocity. Stand-alone devices with good isolation performance have been reported. The integration with III-V host material however remains an issue. The best reported result demonstrated isolation not higher than $5 \mathrm{~dB}$ in a device several millimeters in length. ${ }^{2}$

A different research approach is based on the requirement that for monolithic integration, the isolator structure should be very similar to that of the laser it is to be integrated with. If, in a standard semiconductor optical amplifier (SOA), an adequately magnetized ferromagnetic metal is placed very close to the guiding region, the MO Kerr effect induces a nonreciprocal complex shift of the complex effective index of the guided mode. In other words, the modal absorption is different in both propagation directions. The remaining loss in the forward direction can be compensated for by current injection in the active material. The result is a component which-being transparent or amplifying in one direction, while providing loss in the opposite direction-is

${ }^{a)}$ Electronic mail: wouter.vanparys@intec.ugent.be isolating and can be monolithically integrated with InP-based active photonic devices. A configuration for transverse magnetic (TM)-polarized light was theoretically proposed in 1999 (Ref. 3) and demonstrated in $2004 .{ }^{4}$ Recently, a variant for transverse electric-mode operation has been demonstrated. ${ }^{5}$ In spite of the high levels of nonreciprocal absorption that have been reported, all results so far suffer from a large level of insertion loss with consequently an impractically large injection current. In this letter, we present the design, fabrication, and characterization of a TM-mode device demonstrating a high isolation ratio combined with significantly reduced insertion loss.

Figure 1 illustrates the layout and operation principle of the TM-mode waveguide optical isolator configuration. The performance of this isolator is determined by the interplay between the source of the nonreciprocal effect-the laterally magnetized ferromagnetic metal film - and the amount of TM-polarized gain that can be provided by the active core to compensate the absorption in the metal. Optimization of the device performance is therefore based on the development of an active material system with the highest possible TMselective material gain and the use of a low-absorbing ferromagnetic metal with strong MO properties.

At the operation wavelength of $1300 \mathrm{~nm} \mathrm{AlGaInAs/InP}$ multiple quantum well (MQW) active material has shown considerably better gain performance than InGaAsP/InP material, previously used by Vanwolleghem et al. ${ }^{4}$ This is due to the larger conduction-band offset of the first, enhancing electron confinement and reducing carrier leakage. ${ }^{6}$ As a consequence, the current needed for transparency in one propagation direction is lower. The optimized active core is built up of nine $\mathrm{Al}_{0.07} \mathrm{Ga}_{0.56} \mathrm{In}_{0.37} \mathrm{As}$ quantum wells (QWs) with $-1.16 \%$ tensile strain, strain compensating compressive strained $(+0.64 \%) \mathrm{Al}_{0.30} \mathrm{Ga}_{0.08} \mathrm{In}_{0.62} \mathrm{As}$ barriers, and lattice- 


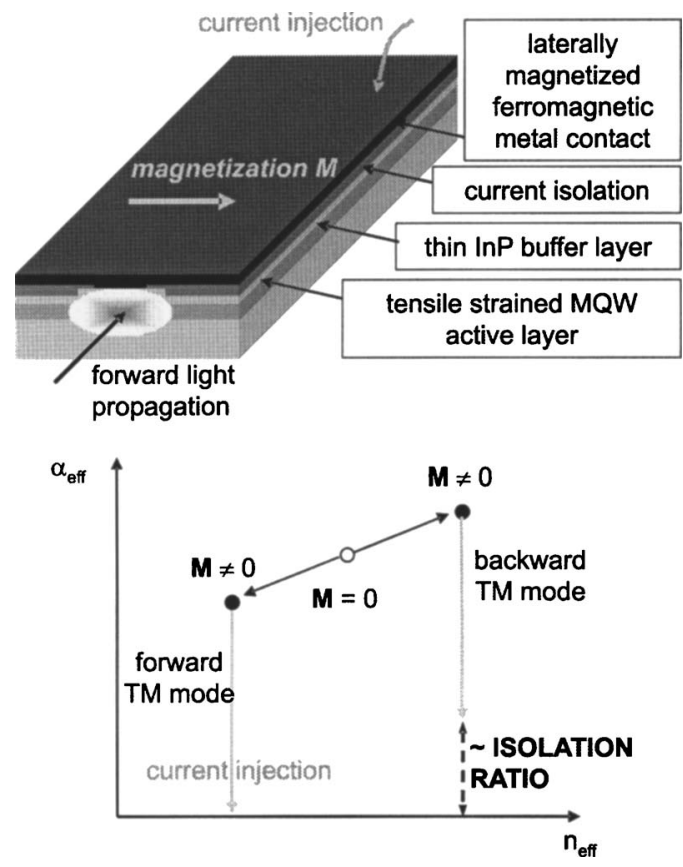

FIG. 1. Schematic layout (top) and operation principle (bottom) of the TMmode optical waveguide isolator; $n_{\text {eff }}$ is the (real) effective index and $\alpha_{\text {eff }}$ is the effective modal loss of the guided mode.

matched $\operatorname{In}_{0.86} \mathrm{Ga}_{0.14} \mathrm{As}_{0.32} \mathrm{P}_{0.68}$ separate confinement heterostructure $(\mathrm{SCH})$ layers. The built-in tensile strain provides TM-selective material gain while suppressing TE gain. Experimental determination of the gain-current density relation of the active material was done on six QWs broad-area (BA) lasers (Fig. 2), indicating a room-temperature transparency current density below $60 \mathrm{~A} / \mathrm{cm}^{2}$ per well. ${ }^{7}$

In this device configuration, the ferromagnetic metal film fulfills two functions: It is the source of the MO nonreciprocal effect and it provides the electric contact for the underlying SOA. The optical (complex refractive index, $n$ ) and MO (off-diagonal element of the dielectric tensor, $\varepsilon_{x z}$ ) constants of several candidate materials have been measured at the wavelength of $1300 \mathrm{~nm}$. While previously $\mathrm{Co}_{90} \mathrm{Fe}_{10}$ has been used as the ferromagnetic material, ${ }^{4}$ these measurements have indicated that the optical and MO properties of the equiatomic $\mathrm{Co}_{50} \mathrm{Fe}_{50}$ alloy are far better suited for the optical isolator. For $\mathrm{Co}_{90} \mathrm{Fe}_{10}$, the extracted parameter values are $n_{\mathrm{C} 090 \mathrm{Fe} 10}=4.65-j 4.83$ for the complex refractive index and $\varepsilon_{x z}$ Co90Fe $10=-1.05-j 1.70$ for the MO constant, while for $\mathrm{Co}_{50} \mathrm{Fe}_{50} n_{\mathrm{Co} 50 \mathrm{Fe} 50}=3.23-j 4.54$ and $\varepsilon_{x z} \mathrm{Co50 \textrm {Fe } 5 0}=-1.70$ $-j$ 1.70. In all optical and MO characterization experiments, the $\exp (+j \omega t)$ sign scheme is used. ${ }^{8}$ The latter material thus

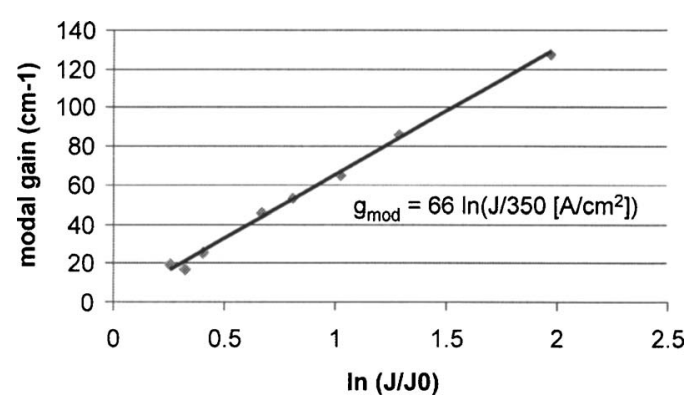

FIG. 2. Experimental gain $\left(g_{\text {mod }}\right)$-current density $(J)$ relation of the tensile strained AlGaInAs MQW active material, measured on six QWs BA lasers.
TABLE I. Details of the layer structure with the optimized thickness values.

\begin{tabular}{|c|c|c|}
\hline Layer & Material & Thickness (nm) \\
\hline Contact & $\mathrm{In}_{0.54} \mathrm{Ga}_{0.46} \mathrm{As}$ & 15.0 \\
\hline Contact & $\mathrm{In}_{0.81} \mathrm{Ga}_{0.19} \mathrm{As}_{0.41} \mathrm{P}_{0.59}$ & 100.0 \\
\hline Cladding & InP & 280.0 \\
\hline $\mathrm{SCH}$ & $\mathrm{In}_{0.86} \mathrm{Ga}_{0.14} \mathrm{As}_{0.32} \mathrm{P}_{0.68}$ & 15.0 \\
\hline Barrier & $\mathrm{Al}_{0.30} \mathrm{Ga}_{0.08} \mathrm{In}_{0.62} \mathrm{As}$ & 20.0 \\
\hline Well & $\mathrm{Al}_{0.07} \mathrm{Ga}_{0.56} \mathrm{In}_{0.37} \mathrm{As}$ & $10.0 \times 9.0$ \\
\hline Barrier & $\mathrm{Al}_{0.30} \mathrm{Ga}_{0.08} \mathrm{In}_{0.62} \mathrm{As}$ & $20.0 \times 9.0$ \\
\hline Cladding & $\mathrm{InP}$ & 1000.0 \\
\hline Substrate & InP & \\
\hline
\end{tabular}

combines a lower optical absorption with a higher MO strength. A low-absorbing semiconductor contact layer structure has been developed to achieve an ohmic electric contact. A hybrid quaternary/ternary $p^{+}$-doped $\left(\mathrm{N}_{\mathrm{Be}}=2.0 \times 10^{17}\right.$ $\left.\mathrm{cm}^{-3} / 3.0 \times 10^{19} \mathrm{~cm}^{-3}\right) \quad \mathrm{In}_{0.81} \mathrm{Ga}_{0.19} \mathrm{As}_{0.41} \mathrm{P}_{0.59} / \mathrm{In}_{0.54} \mathrm{Ga}_{0.46} \mathrm{As}$ bilayer with only a thin absorbing $\operatorname{In}_{0.54} \mathrm{Ga}_{0.46} \mathrm{As}\left(\alpha_{1300 \mathrm{~nm}}\right.$ $\approx 1.5 \mu \mathrm{m}^{-1}$ ) (Ref. 9) top layer provides low contact resistivity combined with minor shielding of the guided mode from the metal.

One-dimensional (1D) simulations with CAMFR, ${ }^{10}$ extended with a perturbation-based algorithm for MO waveguide calculation, ${ }^{11}$ have been used for the design of the geometric device parameters. The experimental gain-current density relation of the active material and the measured material properties of $\mathrm{Co}_{50} \mathrm{Fe}_{50}$ served as the input parameters. The thicknesses of the InP cladding layer and the SCH layers influence both the modal overlap with the ferromagnetic metal and the confinement in the active core and, as such, determine the actual device performance. As an optimization strategy, we chose to use the parameter combination that results in maximum nonreciprocity for a given transparency current density of $10 \mathrm{kA} / \mathrm{cm}^{2}$. In Table I, the designed layer structure with its optimized thickness values is given. The corresponding theoretical isolation ratio equals $152 \mathrm{~dB} / \mathrm{cm}$.

The device was grown with metalorganic vapor phase epitaxy on a $n^{+}$-S-doped InP substrate $\left(\mathrm{N}_{\mathrm{S}}=3.0\right.$ $\left.\times 10^{18} \mathrm{~cm}^{-3}\right)$. The layer structure consists of a Si $n$-doped $\left(\mathrm{N}_{\mathrm{Si}}=10^{18} \mathrm{~cm}^{-3}\right)$ InP cladding layer, the nonintentionally doped optimized active core topped with a $280 \mathrm{~nm}$ thick Be $p$-doped InP cladding $\quad\left(\mathrm{N}_{\mathrm{Be}}=5.0 \times 10^{17} \mathrm{~cm}^{-3} \rightarrow 2.0\right.$ $\times 10^{18} \mathrm{~cm}^{-3}$ ) and the optimized contact structure. The sputter-deposited $50 \mathrm{~nm}$ thick $\mathrm{Co}_{50} \mathrm{Fe}_{50}$ film, capped with a $40 \mathrm{~nm} / 150 \mathrm{~nm} \mathrm{Ti} / \mathrm{Au}$ protective bilayer, was patterned into $2.5 \mu \mathrm{m}$ wide stripes with standard lift off. Ridge waveguides were defined with $\mathrm{CH}_{4}: \mathrm{H}_{2}$ plasma reactive ion etching using these metallic stripes as an etch mask. With this technique, full covering of the ridge with metal is achieved. Processing imperfections caused the actual stripe width to be considerably larger, resulting in wider $(3.2 \mu \mathrm{m})$ and, hence, laterally bimodal ridge waveguides.

Extraction of the isolation strength of the fabricated devices is done by comparing transmitted TM-polarized optical power for magnetization of the ferromagnetic contact in both lateral directions-switching the lateral magnetization direction in the metal film is equivalent to switching between forward and backward propagation direction. TM-polarized incident light from an external cavity tunable laser $(6 \mathrm{dBm}$ output power) is coupled to the waveguide, with the wave- 


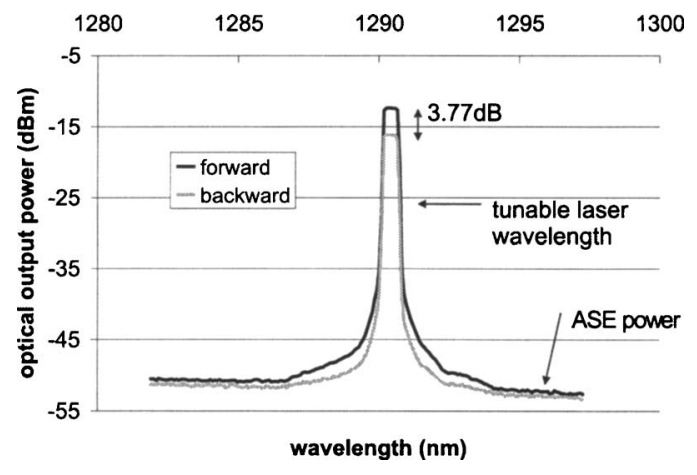

FIG. 3. TM-mode nonreciprocal loss shift at $1290 \mathrm{~nm} .3 .77 \mathrm{~dB}$ is equivalent to an isolation ratio of $99 \mathrm{~dB} / \mathrm{cm}$.

length set close to that of the peak gain of the active material. The output signal is picked up with a single-mode lensed fiber and detected with a spectrum analyzer at a resolution bandwidth of $0.5 \mathrm{~nm}$. The cleaved waveguide facets are uncoated and the cavity length equals $380 \mu \mathrm{m}$. Figure 3 shows the experimental nonreciprocal loss shift for an incident wavelength of $1290 \mathrm{~nm}$. The bias current is $175 \mathrm{~mA}$ and is pulsed (pulse width $0.1 \mu$ s, duty cycle $10 \%$ ) to avoid heating due to the imperfect mounting of the devices. The difference in power level between the "forward" and "backward" signal equals $3.77 \mathrm{~dB}$ which, for a cavity length of $380 \mu \mathrm{m}$, is equivalent to an isolation ratio of $99 \mathrm{~dB} / \mathrm{cm}$. Not only is this value a great improvement with respect to the previously reported TM-mode device, ${ }^{4}$ in addition, the extraction no longer requires fitting to a theoretical model. The discrepancy between the 1D simulation (which predicted $152 \mathrm{~dB} / \mathrm{cm}$ ) and the experiment is believed to result mainly from the lateral multimodality of the active waveguides. The injected-TM-polarized-laser light couples to both the zeroth- and first-order guided modes. The nonreciprocal effect induced on the fundamental mode is considerably larger than that on the first-order mode because the overlap of the latter with the ferromagnetic metal is lower. As the output signal is a mixture of both guided modes, the actual nonreciprocal effect is lower than what can be achieved with this design, provided the device is laterally monomodal. The use of 1D simulations to calculate the theoretical nonreciprocal effect adds an extra difference between simulation and experiment.

The total insertion loss for $175 \mathrm{~mA}$ bias current equals $18 \mathrm{~dB}$. This loss is believed to result only from coupling losses, taking into account that the chip facets are left uncoated and that the waveguides are laterally bimodal which reduces the coupling to the monomode fiber. An estimate of the experimental bias current required for transparency in the forward propagation direction can be made from the observed threshold current of the as-cleaved device combined with the experimental gain-current density relation and the simulated value for the confinement in the active core. The threshold current of $215 \mathrm{~mA}$ corresponds to an estimated bias current of $130 \mathrm{~mA}$. A 1D simulation predicted a value of $121 \mathrm{~mA}$. Consequently, at $175 \mathrm{~mA}$ bias current, the device is amplifying in the forward propagation direction.

In spite of this significant reduction in bias current needed for transparency, the current consumption is still too high for practical implementation of this optical isolator configuration. It is expected that the device performance can be further improved by adopting the design strategy of the thicknesses of the InP cladding layer and the SCH layers. Unlike the current procedure where a fundamental device parameter-the isolation ratio for a given transparency current density-is optimized, a better method would be to find the thickness combination that optimizes practical specifications, such as the total transparency current for a certain total optical isolation.

In summary, we have demonstrated a TM-mode AlGaInAs/InP amplifying optical waveguide isolator with an experimental isolation ratio of $99 \mathrm{~dB} / \mathrm{cm}$. Moderate injection current suffices for transparency of forward propagating light. Good agreement between theoretical and experimental performance is found, with identification of the causes of the remaining discrepancy.

This research has been carried out in the framework of the European Union IST research program ISOLASER. Dr. Philippe Gogol and Professor Pierre Beauvillain are acknowledged for the characterization of the ferromagnetic metals. The authors would like to thank Professor Jan Vandewege and Professor Xing-Zhi Qiu for measurement support.

${ }^{1}$ H. Dötsch, N. Bahlmann, O. Zhuromsky, M. Hammer, L. Wilkens, R. Gerhardt, and P. Hertel, J. Opt. Soc. Am. B 22, 240 (2005).

${ }^{2}$ H. Yokoi, T. Mizumoto, N. Shinjo, N. Futakuchi, and Y. Nakano, Appl. Opt. 39, 6158 (2000).

${ }^{3}$ M. Takenaka and Y. Nakano, in Proceedings of the 11th International Conference on Indium Phosphide and Related Materials, 16-20 May 1999, Davos, Switzerland, pp. 289-292.

${ }^{4}$ M. Vanwolleghem, W. Van Parys, D. Van Thourhout, R. Baets, F. Lelarge, O. Gauthier-Lafaye, B. Thedrez, R. Wirix-Speetjens, and L. Lagae, Appl. Phys. Lett. 85, 3980 (2004).

${ }^{5} \mathrm{H}$. Shimizu and Y. Nakano, in Proceedings of the Optical Fiber Communication Conference, 6-11 March 2005, Anaheim, CA, PDP18.

${ }^{6}$ C. E. Zah, R. Bhat, B. N. Pathak, F. Favire, W. Lin, M. C. Wang, N. C. Andreadakis, D. M. Hwang, M. A. Koza, T. P. Lee, Z. Wang, D. Darby, D. Flanders, and J. J. Hsieh, IEEE J. Quantum Electron. 30, 511 (1994).

${ }^{7}$ J. Decobert, N. Lagay, C. Cuisin, B. Dagens, B. Thedrez, and F. Laruelle, J. Cryst. Growth 272, 542 (2004).

${ }^{8}$ R. Atkinson and P. H. Lissberger, Appl. Opt. 31, 6076 (1992).

${ }^{9}$ D. A. Humphreys, R. J. King, D. Jenkins, and A. J. Moseley, Electron. Lett. 21, 1187 (1985).

${ }^{10}$ P. Bienstman and R. Baets, Opt. Quantum Electron. 33, 327 (2001).

${ }^{11}$ K. Postava, M. Vanwolleghem, D. Van Thourhout, R. Baets, S. Visnovský, P. Beauvillain, and J. Pistora, J. Opt. Soc. Am. B 22, 261 (2005). 